\title{
Impact of Reduced Kidney Function on Cardiopulmonary Fitness in Patients with Systolic Heart Failure
}

\author{
Peter A. McCullough ${ }^{a}$ Barry A. Franklin ${ }^{a}$ Eric Leifer ${ }^{b} \quad$ Gregg C. Fonarow $^{c}$ \\ for the HF-ACTION Investigators \\ ${ }^{a}$ William Beaumont Hospital, Royal Oak, Mich., ${ }^{\text {b}}$ National Heart, Lung and Blood Institute, Bethesda, Md., and \\ 'Ronald Reagan-UCLA Medical Center, Los Angeles, Calif., USA
}

\section{Key Words}

Heart failure $\cdot$ Chronic kidney disease - Cardiopulmonary fitness • Glomerular filtration rate $\cdot$ Renal insufficiency • Mortality risk

\begin{abstract}
Background: Decreased renal function has been consistently associated with increased mortality among patients with systolic heart failure. The relationship between estimated glomerular filtration rate (eGFR) and other high-risk features including reduced cardiorespiratory fitness has not been previously reported in this patient population. Methods: The HF-ACTION trial was a prospective, randomized trial of exercise therapy versus usual care in patients with systolic heart failure. Patients with class $2-4$ heart failure and a left ventricular ejection fraction of $\leq 35 \%$ were recruited. Serum creatinine was measured up to 1 year prior to entry. The 4-variable modified Modification of Diet in Renal Disease equation was used to calculate eGFR. Peak oxygen consumption (peak $\mathrm{VO}_{2}$ ) was directly measured using gas exchange analysis during progressive exercise testing to volitional fatigue or adverse signs/symptoms. Results: Of 2,091 subjects (mean age $59 \pm 13$ years, with serum creatinine
\end{abstract}

available at baseline), $72 \%$ were men, and 61, 33, and 5\% were Caucasians, African Americans, and others, respectively. Older age, diabetes, and hypertension were all more frequent with declining eGFR. The Pearson correlation between eGFR and peak $\mathrm{VO}_{2}$ was 0.22 ( $\left.p<0.0001\right)$. Age was negatively correlated with both eGFR $(r=-0.44, p<0.0001)$ and peak $\mathrm{VO}_{2}(r=-0.27, \mathrm{p}<0.0001)$. The peak $\mathrm{VO}_{2}$ tended to decline across decreasing levels of eGFR. Individuals with an eGFR $<30 \mathrm{ml} / \mathrm{min} / 1.73 \mathrm{~m}^{2}$ had, on average, 2.1 high-risk features including peak $\mathrm{VO}_{2}<14 \mathrm{ml} / \mathrm{kg} / \mathrm{min}$, age $>75$ years, diabetes, and functional class 3-4 symptoms. Conversely, those with an eGFR $>90 \mathrm{ml} / \mathrm{min} / 1.73 \mathrm{~m}^{2}$ had relatively few (1.0) high-risk characteristics. Conclusions: Reduced renal filtration is associated with impaired cardiorespiratory fitness and a clustering of high-risk features in systolic heart failure patients which portend a more complicated course and higher allcause mortality.

Copyright $\odot 2010$ S. Karger AG, Basel

\section{KARGER}

두 2010 S. Karger AG, Basel

Fax +41613061234 E-Mail karger@karger.ch www.karger.com
Peter A, McCullough, MD, MPH, FACC, FACP, FCCP, FAHA

Divisions of Cardiology, Nutrition and Preventive Medicine

William Beaumont Hospital, Beaumont Health Center

4949 Coolidge, Royal Oak, MI 48073 (USA)

Tel. +1 248655 5948, Fax +1 248655 5901, E-Mail peteramccullough@gmail.com 
We are in the midst of concurrent chronic disease epidemics of congestive heart failure (HF) and chronic kidney disease (CKD) worldwide $[1,2]$. This is marked by increases in incident and prevalent cases of both diseases over the past several decades driven by rising rates of common risk factors for both CKD and HF including obesity, metabolic syndrome, diabetes, and hypertension [3-6]. Measures of renal function can now be calculated with a reasonable degree of accuracy with the use of multivariate equations based on serum creatinine and other demographic variables including age [7]. Previous studies have consistently reported an association between reduced estimated glomerular filtration rate (eGFR) and increased HF mortality [8]. We sought to more fully explain the risk features clustered in those patients with CKD and HF while adjusting for age, cardiorespiratory fitness, and other baseline variables in a large, multicenter randomized trial.

\section{Methods}

\section{Setting}

The Heart Failure: A Controlled Trial Investigating Outcomes of Exercise Training (HF-ACTION) was a prospective, randomized trial of exercise training in patients who were medically stable, with New York Heart Association (NYHA) class 2-4 HF and measured left ventricular ejection fraction $\leq 35 \%$. Recruitment methods for the HF-ACTION have been published elsewhere [9]. The trial was designed to evaluate the composite end point of allcause mortality and all-cause hospitalization over a median follow-up of 30 months in patients who underwent medically supervised and home-based exercise training as compared with controls who received usual care [10].

\section{Study Sample}

A total of 2,331 subjects were recruited from April 2003 through February 2007 at 82 sites within the United States, Canada, and France; however, the study sample was reduced because 240 subjects had no measured serum creatinine recorded at baseline. The remaining 2,091 HF patients served as the study population, providing complete data for analysis. Major exclusion criteria were comorbidities that could interfere with exercise training (e.g. peritoneal dialysis or hemodialysis) and major cardiovascular events within the last 6 months.

\section{Data Collection}

Baseline demographics, clinical history, and objective assessment of clinical signs were gathered by trained research personnel at each site. Subjects underwent peak or symptom-limited cardiopulmonary exercise testing as previously described using a modified Naughton treadmill protocol or a $10 \mathrm{~W} / \mathrm{min}$ incremental cycle ergometry protocol [11]. Heart rate was measured at rest in the supine and standing positions, during each stage of exercise, and throughout a 6-min recovery. Test termination criteria included: patient request; volitional fatigue; increasing chest or leg pain, and electrocardiographic (ECG) abnormalities ( $\geq 2 \mathrm{~mm}$ ST segment depression and/or threatening ventricular arrhythmias).

Respiratory variables, heart rate, and perceived exertion were determined at submaximal and peak exercise. The ECG was monitored continuously by oscilloscope, with 3-channel $\left(\mathrm{V}_{1}, \mathrm{~V}_{5}\right.$, and $\mathrm{aVF}$ ) recordings obtained throughout the exercise test, and 12lead ECGs $(1 \mathrm{mV} / 10 \mathrm{~mm})$ recorded at the end of each stage and during peak exercise. Perception of the intensity of physical effort at submaximal and peak exercise was obtained using the Borg category scale (6-20) [12].

Metabolic data were gathered from standard cardiopulmonary exercise training systems which include a computer assembly for breath-by-breath and on-line 60-second calculations of oxygen consumption $\left(\mathrm{VO}_{2} ; \mathrm{ml} / \mathrm{kg} / \mathrm{min}\right.$ or METs), minute ventilation (VE), carbon dioxide production $\left(\mathrm{VCO}_{2}\right)$, and respiratory exchange ratio (RER; $\mathrm{VCO}_{2} / \mathrm{VO}_{2}$ ). Before each test, the pneumotachometer was referenced according to manufacturer specifications, and the gas analyzers were calibrated with a certified air mixture representing room air $\left(21 \% \mathrm{O}_{2}\right.$ and balance nitrogen) and certified oxygen/carbon dioxide concentrations.

The V-slope method, used by experienced investigators at the HF-ACTION core lab, was applied to determine the ventilatoryderived anaerobic threshold (i.e. the break point in linearity when $\mathrm{VCO}_{2}$ was plotted as a function of $\mathrm{VO}_{2}$ ), expressed as a percentage of the peak $\mathrm{VO}_{2}$. This method has been reported to be a sensitive, reliable, noninvasive technique for the detection of the onset of metabolic acidosis $[13,14]$. The peak $\mathrm{VO}_{2}$ was defined as the highest $\mathrm{VO}_{2}$ value for a given 15 - or 20 -second interval within the last $90 \mathrm{~s}$ of exercise or the first $30 \mathrm{~s}$ of recovery [11]. We also computed the slopes of the relation between $\mathrm{VE}$ and $\mathrm{VO}_{2}$, and between $\mathrm{VE}$ and $\mathrm{VCO}_{2}$, as markers of breathing economy and functional limitations, respectively.

\section{Calculation of Glomerular Filtration Rate}

Measurement of serum creatinine was obtained from the recorded serum creatinine (up to 1 year prior to study enrollment) and performed using the central laboratory at each center. eGFRs $\left(\mathrm{ml} / \mathrm{min} / 1.73 \mathrm{~m}^{2}\right)$ were calculated using the Levey modified Modification of Diet in Renal Disease formula [186.3 $\times$ (serum creatinine $\left.^{-1.154}\right) \times\left(\right.$ age $\left.^{-0.203}\right)$ ]; calculated values were multiplied by 0.742 for women and by 1.21 for African Americans [7]. Calculated eGFR values were categorized as $<30,30-59,60-89$, and $\geq 90 \mathrm{ml} / \mathrm{min} / 1.73 \mathrm{~m}^{2}$ based on the National Kidney Foundation Kidney Disease Outcomes Quality Initiative classification of kidney function; eGFR values $<60 \mathrm{ml} / \mathrm{min} / 1.73 \mathrm{~m}^{2}$ were considered abnormal and indicative of moderately reduced kidney function.

Statistical Analysis

Baseline characteristics were reported in counts and proportions or means \pm standard deviations as appropriate. The Pearson correlation coefficient was used for bivariate correlations of continuous variables, and the Spearman correlation coefficient was used for bivariate correlations of continuous variables with eGFR category. The Pearson correlation was used to evaluate the bivariate relationship between eGFR and peak $\mathrm{VO}_{2}$ as continuous variables. The Cochran-Mantel-Haenszel test was applied to test for trend of categorical variables across eGFR categories. The general linear model was used to evaluate the relevant predictor variables to eGFR as a dependent variable. A p value $<0.05$ was considered statistically significant. 
Table 1. Baseline characteristics, by CKD stage

\begin{tabular}{|c|c|c|c|c|c|c|}
\hline \multirow[t]{2}{*}{ Characteristic } & \multicolumn{5}{|c|}{ CKD level } & \multirow{2}{*}{$\begin{array}{l}\mathrm{p} \text { value } \\
\text { for trend }\end{array}$} \\
\hline & all & $1(>90)$ & $2(89-60)$ & $3(59-30)$ & $4(29-15)$ & \\
\hline Number & 2,091 & 338 & 947 & 728 & 78 & \\
\hline \multicolumn{7}{|l|}{ Demographics } \\
\hline Age, years & $59 \pm 13$ & $50 \pm 13$ & $57 \pm 12$ & $65 \pm 11$ & $67 \pm 12$ & $<0.0001$ \\
\hline Age $>75$ years, $\%$ & 11 & 3 & 6 & 19 & 31 & $<0.0001$ \\
\hline Male, $\%$ & 72 & 70 & 73 & 74 & 70 & 0.33 \\
\hline Caucasian, $\%$ & 61 & 42 & 60 & 71 & 71 & $<0.0001$ \\
\hline African American, \% & 33 & 53 & 34 & 24 & 26 & $<0.0001$ \\
\hline Other race, $\%$ & 5 & 5 & 5 & 5 & 4 & 0.58 \\
\hline \multicolumn{7}{|l|}{ Medical history, \% } \\
\hline Hypertension & 61 & 57 & 59 & 63 & 68 & 0.02 \\
\hline Diabetes mellitus & 33 & 33 & 26 & 40 & 45 & $<0.0001$ \\
\hline Chronic obstructive pulmonary disease & 11 & 7 & 11 & 13 & 13 & 0.008 \\
\hline Stable angina & 26 & 25 & 26 & 28 & 22 & 0.53 \\
\hline Prior myocardial infarction & 43 & 27 & 42 & 50 & 53 & $<0.0001$ \\
\hline Prior coronary artery bypass surgery & 26 & 15 & 22 & 35 & 36 & $<0.0001$ \\
\hline \multicolumn{7}{|l|}{ Chronic prescribed medications, $\%$} \\
\hline Angiotensin-converting enzyme inhibitors & 74 & 81 & 75 & 71 & 65 & 0.0001 \\
\hline $\mathrm{ARB}$ & 24 & 20 & 23 & 27 & 22 & 0.04 \\
\hline Spironolactone/eplerenone & 46 & 45 & 48 & 45 & 35 & 0.16 \\
\hline$\beta$-Blockers & 95 & 96 & 95 & 94 & 95 & 0.19 \\
\hline Nitrates & 25 & 18 & 23 & 30 & 32 & $<0.0001$ \\
\hline Calcium channel blockers & 7 & 7 & 7 & 7 & 3 & 0.77 \\
\hline Loop diuretics & 79 & 70 & 76 & 87 & 88 & $<0.0001$ \\
\hline Digoxin & 46 & 46 & 45 & 48 & 35 & 0.92 \\
\hline
\end{tabular}

CKD level: based on the National Kidney Foundation Kidney Disease Outcomes Quality Initiative stage in eGFR, expressed as $\mathrm{ml} / \mathrm{min} / 1.73 \mathrm{~m}^{2}$ (figures in parentheses). ARB = Angiotensin II receptor blocker. Please note that CKD stages 1 and 2 were not confirmed by the presence of markers of kidney damage.

\section{Results}

\section{Baseline Characteristics}

The demographics for the study sample $(\mathrm{n}=2,091)$ were as follows: age $59 \pm 13$ years (range 19-90); $72 \%$ male; 61\% Caucasians, 33\% African Americans, and 5\% others. Of note, those with advanced CKD were more likely to be Caucasians than African Americans, consistent with a multinational population including Canadian and European sites. Risk factors for HF or CKD included: history of hypertension in $61 \%$, diabetes in $33 \%$, and myocardial infarction in $43 \%$. The baseline characteristics stratified by eGFR level are shown in table 1 . Those with advanced CKD tended to be older, and more commonly had higher rates of expected risk factors for both $\mathrm{HF}$ and $\mathrm{CKD}$, including hypertension and diabetes. In addition, advanced CKD patients where more likely to have had a prior myocardial infarction or have undergone coronary artery bypass surgery $(\mathrm{p}<0.0001$ for both).

\section{Clinical Examination Variables}

Table 2 summarizes the baseline clinical examination variables. Of note, patients had blood pressures that were in the normal range, averaging $114 / 70 \mathrm{~mm} \mathrm{Hg}$. There were no differences in baseline systolic blood pressures across the CKD groups. The severity of HF symptoms as reflected in the NYHA functional classification and the objective impairment in 6-min walk distance tended to be greater in those with reduced eGFR. The degree of left ventricular systolic impairment and dilation tended to be lower across the groups by declining eGFR. 
Table 2. Clinical examination variables, by CKD stage

\begin{tabular}{|c|c|c|c|c|c|c|}
\hline \multirow[t]{2}{*}{ Characteristic } & \multicolumn{5}{|l|}{ CKD level } & \multirow{2}{*}{$\begin{array}{l}\mathrm{p} \text { value } \\
\text { for trend }\end{array}$} \\
\hline & all & $1(>90)$ & $2(89-60)$ & $3(59-30)$ & $4(29-15)$ & \\
\hline Number & 2,091 & 338 & 947 & 728 & 78 & \\
\hline \multicolumn{7}{|l|}{ Physical exam } \\
\hline BMI & $31 \pm 7$ & $33 \pm 9$ & $31 \pm 7$ & $30 \pm 6$ & $29 \pm 7$ & $<0.0001$ \\
\hline Heart rate, bpm & $71 \pm 12$ & $73 \pm 12$ & $71 \pm 12$ & $70 \pm 10$ & $68 \pm 10$ & 0.0001 \\
\hline Systolic blood pressure, $\mathrm{mm} \mathrm{Hg}$ & $114 \pm 18$ & $116 \pm 18$ & $113 \pm 18$ & $114 \pm 19$ & $115 \pm 20$ & 0.26 \\
\hline Diastolic blood pressure, $\mathrm{mm} \mathrm{Hg}$ & $70 \pm 11$ & $73 \pm 12$ & $71 \pm 11$ & $69 \pm 11$ & $69 \pm 11$ & $<0.0001$ \\
\hline Euro QOL & $65 \pm 20$ & $66 \pm 19$ & $66 \pm 19$ & $64 \pm 20$ & $68 \pm 17$ & 0.54 \\
\hline NYHA class $(2 / 3 / 4), \%$ & $63 / 36 / 1$ & $70 / 30 / 1$ & $67 / 32 / 1$ & $56 / 42 / 1$ & $52 / 45 / 3$ & $<0.0001$ \\
\hline CCS class $(0 / 1 / 2 / 3+4), \%$ & $84 / 9 / 6 / 2$ & $84 / 9 / 5 / 1$ & $82 / 9 / 6 / 2$ & $82 / 9 / 7 / 2$ & $88 / 4 / 4 / 4$ & 0.88 \\
\hline 6-Min walk distance, feet & $365 \pm 105$ & $384 \pm 99$ & $376 \pm 103$ & $342 \pm 104$ & $320 \pm 88$ & $<0.0001$ \\
\hline \multicolumn{7}{|l|}{ Echocardiogram } \\
\hline LVEF, $\%$ & $25 \pm 7$ & $26 \pm 8$ & $25 \pm 8$ & $25 \pm 7$ & $25 \pm 7$ & 0.03 \\
\hline LVIDD, cm & $6.6 \pm 1.2$ & $6.7 \pm 1.2$ & $6.6 \pm 1.2$ & $6.6 \pm 1.2$ & $6.7 \pm 1.3$ & 0.88 \\
\hline \multicolumn{7}{|l|}{ Laboratories } \\
\hline Creatinine, mg/dl & $1.3 \pm 0.8$ & $0.8 \pm 0.1$ & $1.1 \pm 0.2$ & $1.6 \pm 0.3$ & $3.8 \pm 2.8$ & $<0.0001$ \\
\hline
\end{tabular}

CKD level: based on the National Kidney Foundation Kidney Disease Outcomes Quality Initiative stage in eGFR, expressed as $\mathrm{ml} / \mathrm{min} / 1.73 \mathrm{~m}^{2}$ (figures in parentheses). BMI = Body mass index; $\mathrm{QOL}=$ quality of life; CCS = Canadian Cardiovascular Society angina class; LVEF = left ventricular ejection fraction, LVIDD = left ventricular internal diastolic diameter. Please note that CKD stages 1 and 2 were not confirmed by the presence of markers of kidney damage.

Table 3. Results from cardiopulmonary stress tests

\begin{tabular}{|c|c|c|c|c|c|c|}
\hline \multirow[t]{2}{*}{ Characteristic } & \multicolumn{5}{|l|}{ CKD level } & \multirow{2}{*}{$\begin{array}{l}\mathrm{p} \text { value } \\
\text { for trend }\end{array}$} \\
\hline & all & $1(>90)$ & $2(89-60)$ & $3(59-30)$ & $4(29-15)$ & \\
\hline Number & 2,091 & 338 & 947 & 728 & 78 & \\
\hline Resting HR, bpm & $71 \pm 11$ & $73 \pm 12$ & $71 \pm 12$ & $70 \pm 10$ & $68 \pm 10$ & 0.0001 \\
\hline Exercise duration, min & $9.8 \pm 4.0$ & $10.6 \pm 4.1$ & $10.4 \pm 4.0$ & $8.6 \pm 3.5$ & $7.7 \pm 3.1$ & $<0.0001$ \\
\hline HR at peak exercise, bpm & $120 \pm 22$ & $129 \pm 23$ & $123 \pm 21$ & $111 \pm 20$ & $107 \pm 22$ & $<0.0001$ \\
\hline Perceived exertion (6-20) & $16.6 \pm 2.4$ & $16.9 \pm 2.3$ & $16.6 \pm 2.5$ & $16.5 \pm 2.4$ & $15.9 \pm 2.5$ & 0.002 \\
\hline Peak respiratory exchange ratio & $1.09 \pm 0.11$ & $1.08 \pm 0.11$ & $1.09 \pm 0.11$ & $1.09 \pm 0.12$ & $1.11 \pm 0.11$ & 0.03 \\
\hline Time to $\mathrm{RER}=1.0, \mathrm{~min}$ & $7.8 \pm 3.2$ & $8.5 \pm 3.3$ & $8.3 \pm 3.1$ & $6.8 \pm 3.0$ & $5.9 \pm 2.4$ & $<0.0001$ \\
\hline Peak $\mathrm{VO}_{2}, \mathrm{ml} / \mathrm{kg} / \mathrm{min}$ & $14.9 \pm 4.7$ & $15.9 \pm 4.6$ & $15.7 \pm 4.9$ & $13.5 \pm 4.1$ & $11.7 \pm 3.2$ & $<0.0001$ \\
\hline Peak $\mathrm{VO}_{2}<14.0 \mathrm{ml} / \mathrm{kg} / \mathrm{min}, \%$ & 46 & 37 & 38 & 59 & 78 & $<0.0001$ \\
\hline $\begin{array}{l}\mathrm{VO}_{2} \text { at anaerobic threshold, } \\
\mathrm{ml} / \mathrm{kg} / \mathrm{min}\end{array}$ & $10.8 \pm 2.7$ & $11.3 \pm 2.6$ & $11.1 \pm 2.7$ & $10.0 \pm 2.4$ & $9.0 \pm 2.3$ & $<0.0001$ \\
\hline
\end{tabular}

CKD level: based on the National Kidney Foundation Kidney Disease Outcomes Quality Initiative stage in eGFR, expressed as $\mathrm{ml} / \mathrm{min} / 1.73 \mathrm{~m}^{2}$ (figures in parentheses). HR = Heart rate; Please note that CKD stages 1 and 2 were not confirmed by the presence of markers of kidney damage. 


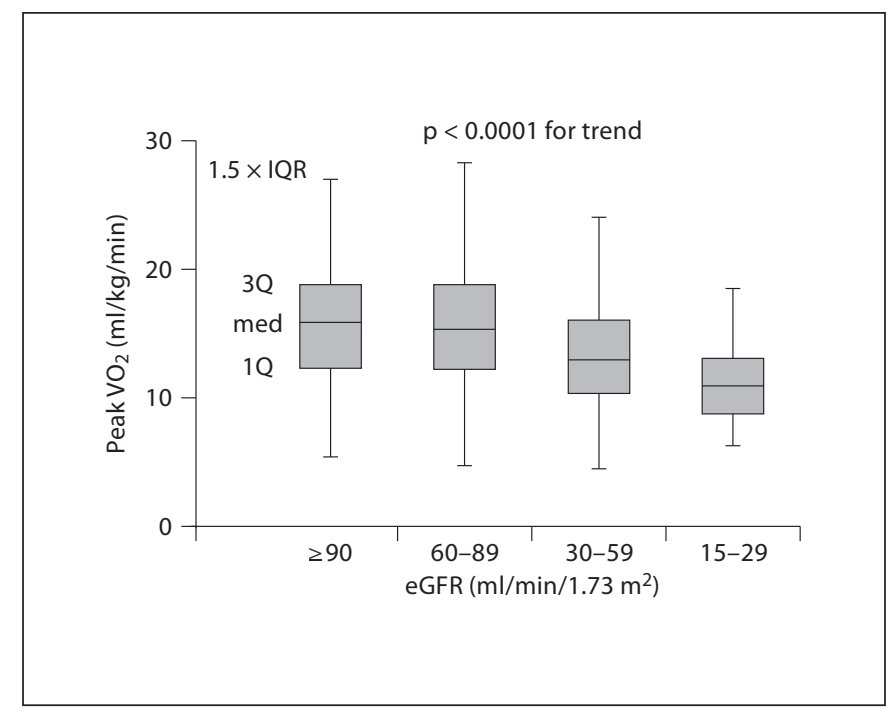

Fig. 1. Box plot of eGFR and peak $\mathrm{VO}_{2}$ levels obtained at baseline across CKD groups. IQR = Interquartile range.

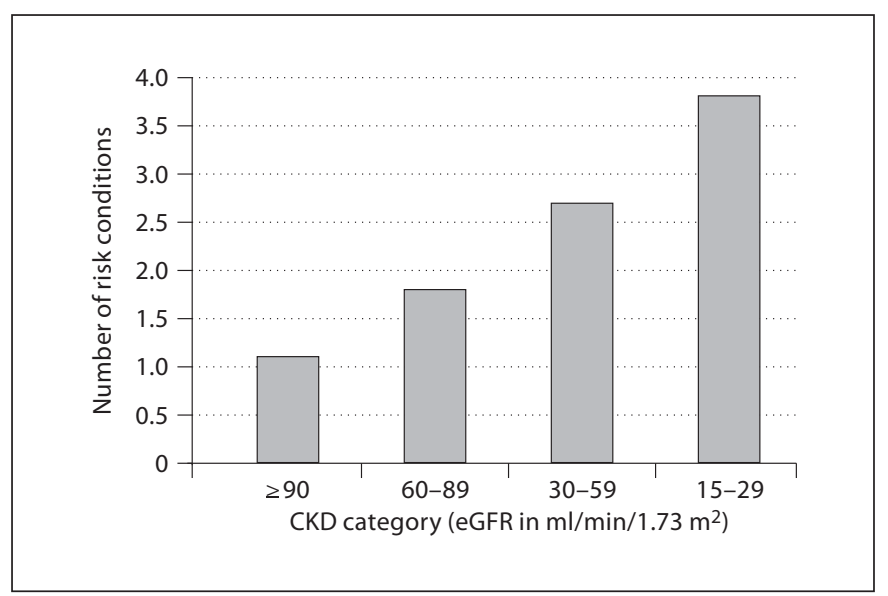

Fig. 3. Median number of high-risk features stratified by eGFR category.

\section{Glomerular Filtration Rate and Cardiopulmonary \\ Exercise Test Results}

The results of the baseline cardiopulmonary exercise tests, including the mean peak $\mathrm{VO}_{2}$ values per level of eGFR, are shown in table 3. The mean peak $\mathrm{VO}_{2}$ was lower in a graded fashion over cohorts of declining eGFR. In those categories with eGFR $<60 \mathrm{ml} / \mathrm{min} / 1.73 \mathrm{~m}^{2}$, the mean peak $\mathrm{VO}_{2}$ values were consistently lower than the population $(\mathrm{n}=2,091)$ median $(14.3 \mathrm{ml} / \mathrm{kg} / \mathrm{min})$. The

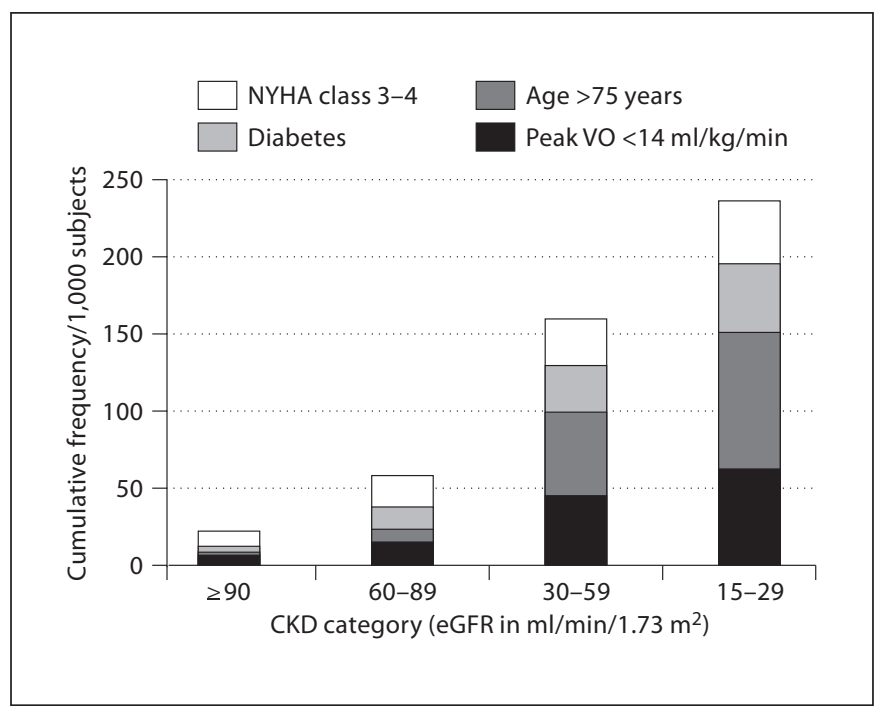

Fig. 2. Stacked bar graph showing the cumulative frequency per 1,000 subjects of high-risk features stratified by eGFR category.

mean peak RER was similar across groups, suggesting comparable somatic anaerobiosis and volitional fatigue. The $\mathrm{VO}_{2}$ at the anaerobic threshold and the time to RER $=1.0$, however, were both modestly lower in the cohort with the most severely reduced renal function. Figure 1 displays a box plot of the peak $\mathrm{VO}_{2}$ results according to the eGFR category. The Pearson correlation between eGFR and peak $\mathrm{VO}_{2}$ was $0.22(\mathrm{p}<0.0001)$. Age was inversely correlated with both eGFR $(\mathrm{r}=-0.44, \mathrm{p}<0.0001)$ and peak $\mathrm{VO}_{2}(\mathrm{r}=-0.27, \mathrm{p}<0.0001)$.

\section{Clustering of High-Risk Features}

Figure 2 shows the relative cumulative frequency per 1,000 of high-risk features including peak $\mathrm{VO}_{2}<14 \mathrm{ml} /$ $\mathrm{kg} / \mathrm{min}$, age $>75$ years, diabetes, and functional class 3-4 symptoms. The relative proportions of older age and peak $\mathrm{VO}_{2}<14 \mathrm{ml} / \mathrm{kg} / \mathrm{min}$ increased in a graded fashion over the lower eGFR categories and were the 2 most frequent high-risk characteristics among those with an eGFR $<60$ $\mathrm{ml} / \mathrm{min} / 1.73 \mathrm{~m}^{2}$. Figure 3 gives the median number of high-risk conditions in patients according to the eGFR category. Among those with eGFR $<30 \mathrm{ml} / \mathrm{min} / 1.73 \mathrm{~m}^{2}$, $89 \%$ of the subjects had at least 1 high-risk characteristic, and $15 \%$ of the subjects had all 4 high-risk features. The highest NYHA class (mean 2.68) characterized those who were in both the lowest peak $\mathrm{VO}_{2}$ quartile $(\leq 11.3$ $\mathrm{ml} / \mathrm{kg} / \mathrm{min})$ and the eGFR category $(<30 \mathrm{ml} / \mathrm{min} / 1.73$ $\left.\mathrm{m}^{2}\right)$. 


\section{Independent Associations with Significant CKD}

Using multiple logistic regression, only age (OR $=1.05$ per year increase, $95 \%$ CI 1.03-1.08, p < 0.0001) and peak $\mathrm{VO}_{2}(\mathrm{OR}=1.18$ per $1 \mathrm{ml} / \mathrm{kg} / \mathrm{min}$ decrease, $95 \%$ CI 1.09 $1.25, \mathrm{p}<0.0001)$ were independently associated with a baseline eGFR $<30 \mathrm{ml} / \mathrm{min} / 1.73 \mathrm{~m}^{2}$ (stage 4 and higher CKD). When eGFR was modeled as a continuous outcome variable, older age, lower peak $\mathrm{VO}_{2}$, lower left ventricular ejection fraction, higher NHYA functional class, and African American race were all found to be statistically significant $(\mathrm{p}<0.05)$. The overall $\mathrm{R}^{2}$ for the model was 0.23 , which can be interpreted as indicating that $23 \%$ of the variability in renal filtration function was explained by differences in baseline variables.

\section{Discussion}

We found that reduced renal function was modestly associated with lower peak $\mathrm{VO}_{2}$ in this baseline analysis. This relationship was highly driven by age as there was a 17-year difference between the highest and the lowest eGFR categories. We believe that cardiac function, more than underlying pulmonary disease, accounted for the severely reduced peak $\mathrm{VO}_{2}$ values, given that $85 \%$ of the subjects had no history of chronic obstructive lung disease and all had symptomatic HF. Holding age constant in the multivariate analysis, peak $\mathrm{VO}_{2}$ was independently associated with reduced eGFR. The $\mathrm{VO}_{2}$ at the anaerobic threshold and the time to RER $=1.0$ were progressively lower as renal function worsened, suggesting that uremia may be related to insufficient oxygen delivery to activate muscles and the associated lactic acidemia. We do not have published reports of expected cardiopulmonary test results in patients with CKD but normal cardiac function to make comparisons. The categories of eGFR according to the National Kidney Foundation stages of CKD segregated patients into groups with a graded increase in the number and cumulative frequency of combined high-risk features, including older age, diabetes, more severe symptoms, and lower cardiorespiratory fitness. Importantly, significant CKD was independently associated with multiple variables that are associated with increased mortality in patients with HF. We did not have the etiology of CKD recorded and cannot make conclusions on whether one form of CKD is different from another. Nonetheless, these data are consistent with the notion that CKD is a high-risk state for patients with HF and represents a complicated clustering of factors that are related to all-cause mortality [15].

Reduced Kidney Function and

Cardiopulmonary Fitness
Reduced renal filtration function is associated with salt and water retention and chronic volume overload which may exacerbate HF symptoms. Indeed, those with the most impaired renal function and the lowest peak $\mathrm{VO}_{2}$ had the highest physician-assigned NYHA class and the worst HF symptoms. These patients may indeed have the presence of a chronic cardiorenal syndrome, where either the HF worsens kidney function (type 2) or vice versa (type 4) [16]. In cardiorenal syndromes, uremia may play an additional role in reducing myocardial contractility and systolic performance [17]. Metabolic acidosis associated with progressive renal failure also plays a role in the impairment of cellular transport of electrolytes and oxygen, which affects cardiovascular and cellular functions [18]. Hormonal anomalies in CKD include reduced levels of 1,25-dihydroxyvitamin D and erythropoietin, both of which have been implicated in left ventricular remodeling and HF $[19,20]$. Lastly, CKD is associated with increased markers of inflammation and oxidative stress $[21,22]$. Although the clinical significance of these indicators in HF remains unclear, it appears that in those patients with the lowest eGFR, both inflammation and oxidative stress may serve to worsen symptomology and functional capacity. Collectively, these pathologic changes may be responsible, at least in part, for the impaired exercise tolerance in patients with the most compromised eGFR. It has been observed that in end-stage renal disease patients with left ventricular impairment, renal transplantation results in an increase in left ventricular ejection fraction from 32 to $52 \%$ and improved functional status, suggesting that $\mathrm{CKD}$ is playing a reversible role in the depression of cardiopulmonary performance [23].

We recognize that age is an important confounder for the eGFR measurement (part of the estimating equation) and for peak $\mathrm{VO}_{2}(10 \%$ per decade decline seen in normal aging) [24]. Age was correlated with both measures in our study, suggesting that the senescent decline in both cardiorespiratory and renal function may play a role in the progression of adverse left ventricular remodeling and attendant HF symptoms [25, 26]. Importantly, the triad of older age, low functional capacity, and reduced renal filtration may identify a particularly frail population that is more prone to medication adverse events, complications during hospitalizations, and a greater susceptibility to mortality with major adverse events over the natural history of HF [27-29]. The rates of $\beta$-blocker use were high (approx. 95\%) and similar $(\mathrm{p}=0.019)$ across the eGFR groups and, hence, were unlikely to confound the results. Our data support this notion to some degree with lower rates of angiotensin-converting en-

Am J Nephrol 2010;32:226-233 
zyme inhibitors and higher rates of myocardial infarction and bypass surgery in those with reduced renal function at baseline.

Our study has all the limitations of a cross-sectional analysis from a large randomized trial. Selection bias for entry into the trial invariably yielded a younger and more robust group of HF patients than those normally seen in clinical practice. Our subjects were further restricted to having systolic HF, thus, we cannot generalize our findings to those with pure diastolic HF. Serum creatinine was obtained from clinical records and not measured in a core lab, hence, differences in assay types and standardization invariably contributed to variation in eGFR. Unfortunately, we did not measure arterial blood gas values, levels of vitamin D, or erythropoietin. Moreover, we did not address the complicated issue of anemia, CKD, and HF severity, and did not include hemoglobin in the present analysis, since it has been reserved for future manuscripts. Lastly, we did not have advanced biologic measures of inflammation and oxidative stress or other bio- markers to elucidate the pathophysiologic mechanisms relating chronic failure of both the heart and kidneys [30].

\section{Conclusion}

Reduced renal filtration function is associated with a markedly impaired functional capacity and a clustering of high-risk features in systolic HF patients which portend a more complicated course and higher all-cause mortality.

\section{Acknowledgements}

Gregg C. Fonarow is a consultant/honorarium recipient from Novartis (significant), and a honorarium recipient from MerckSchering Plough (significant). The study was supported/funded by the National Institutes of Health, National Heart, Lung and Blood Institute.

\section{References}

1 McCullough PA, Philbin EF, Spertus JA, Kaatz S, Sandberg KR, Weaver WD: Confirmation of a heart failure epidemic: findings from the Resource Utilization Among Congestive Heart Failure (REACH) Study. J Am Coll Cardiol 2002;39:60-69.

-2 Szczech LA, Harmon W, Hostetter TH, Klotman PE, Powe NR, Sedor JR, Smedberg P, Himmelfarb J: World Kidney Day 2009: problems and challenges in the emerging epidemic of kidney disease. J Am Soc Nephrol 2009;20:453-455.

- 3 Whaley-Connell AT, Sowers JR, Stevens LA, McFarlane SI, Shlipak MG, Norris KC, Chen SC, Qiu Y, Wang C, Li S, Vassalotti JA, Collins AJ, Kidney Early Evaluation Program Investigators: CKD in the United States: Kidney Early Evaluation Program (KEEP) and National Health and Nutrition Examination Survey (NHANES) 1999-2004. Am J Kidney Dis 2008;51(4 suppl 2):S13-S20.

-4 Whaley-Connell AT, Sowers JR, McFarlane SI, Norris KC, Chen SC, Li S, Qiu Y, Wang C, Stevens LA, Vassalotti JA, Collins AJ, Kidney Early Evaluation Program Investigators: Diabetes mellitus in CKD: Kidney Early Evaluation Program (KEEP) and National Health and Nutrition and Examination Survey (NHANES) 1999-2004. Am J Kidney Dis 2008;51(4 suppl 2):S21-S29.

5 Artham SM, Lavie CJ, Patel HM, Ventura HO: Impact of obesity on the risk of heart failure and its prognosis. J Cardiometab Syndr 2008;3:155-161.
6 Zalesin KC, Franklin BA, Miller WM, Peterson ED, McCullough PA: Impact of obesity on cardiovascular disease. Endocrinol Metab Clin North Am 2008;37:663-684.

7 Vassalotti JA, Stevens LA, Levey AS: Testing for chronic kidney disease: a position statement from the National Kidney Foundation. Am J Kidney Dis 2007;50:169-180.

$\rightarrow 8$ Smith GL, Lichtman JH, Bracken MB, Shlipak MG, Phillips CO, DiCapua P, Krumholz HM: Renal impairment and outcomes in heart failure: systematic review and metaanalysis. J Am Coll Cardiol 2006;47:19871996.

9 Whellan DJ, O'Connor CM, Lee KL, Keteyian SJ, Cooper LS, Ellis SJ, Leifer ES, Kraus WE, Kitzman DW, Blumenthal JA, Rendall DS, Houston-Miller N, Fleg JL, Schulman KA, Piña IL, HF-ACTION Trial Investigators: Heart failure and a controlled trial investigating outcomes of exercise training (HF-ACTION): design and rationale. Am Heart J 2007;153:201-211.

10 O'Connor CM, Whellan DJ, Lee KL, Keteyian SJ, Cooper LS, Ellis SJ, Leifer ES, Kraus WE, Kitzman DW, Blumenthal JA, Rendall DS, Miller NH, Fleg JL, Schulman KA, McKelvie RS, Zannad F, Piña IL, HF-ACTION Investigators: Efficacy and safety of exercise training in patients with chronic heart failure: HF-ACTION randomized controlled trial. JAMA 2009;301:1439-1450.
11 Bensimhon DR, Leifer ES, Ellis SJ, Fleg JL, Keteyian SJ, Piña IL, Kitzman DW, McKelvie RS, Kraus WE, Forman DE, Kao AJ, Whellan DJ, O'Connor CM, Russell SD, HF-ACTION Trial Investigators: Reproducibility of peak oxygen uptake and other cardiopulmonary exercise testing parameters in patients with heart failure (from the Heart Failure and A Controlled Trial Investigating Outcomes of exercise traiNing). Am J Cardiol 2008;102: 712-717.

12 Borg G: Borg's Perceived Exertion and Pain Scales. Champaigne, Human Kinetics, 1998.

13 Beaver WL, Wasserman K, Whipp BJ: A new method for detecting the anaerobic threshold by gas exchange. J Appl Physiol 1986;60: 2020-2027.

14 Sue DY, Wasserman K, Moricca RB, et al: Metabolic acidosis during exercise in patients with chronic obstructive pulmonary disease. Use of the V-slope method for anaerobic threshold determination. Chest 1988;94:931-938

15 Levey AS, Atkins R, Coresh J, Cohen EP, Collins AJ, Eckardt KU, Nahas ME, Jaber BL, Jadoul M, Levin A, Powe NR, Rossert J, Wheeler DC, Lameire N, Eknoyan G: Chronic kidney disease as a global public health problem: approaches and initiatives - A position statement from Kidney Disease Improving Global Outcomes. Kidney Int 2007; 72:247-259. 
-16 Ronco C, McCullough P, Anker SD, Anand I, Aspromonte N, Bagshaw SM, Bellomo R, Berl T, Bobek I, Cruz DN, Daliento L, Davenport A, Haapio M, Hillege H, House AA, Katz N, Maisel A, Mankad S, Zanco P, Mebazaa A, Palazzuoli A, Ronco F, Shaw A, Sheinfeld G, Soni S, Vescovo G, Zamperetti N, Ponikowski P, for the Acute Dialysis Quality Initiative (ADQI) consensus group: Cardiorenal syndromes: report from the consensus conference of the acute dialysis quality initiative. Eur Heart J 2010;31:703-711.

17 Weisensee D, Schnaars Y, Schoeppe W, Bereiter-Hahn J, Löw-Friedrich I: Potential uremic toxins modulate energy metabolism of cardiac myocytes in vitro. Exp Nephrol 1997;5:194-200.

- 18 Yerkey MW, Kernis SJ, Franklin BA, Sandberg KR, McCullough PA: Renal dysfunction and acceleration of coronary disease. Heart 2004;90:961-966.

-19 Zittermann A, Schleithoff SS, Koerfer R: Vitamin $\mathrm{D}$ insufficiency in congestive heart failure: why and what to do about it? Heart Fail Rev 2006;11:25-33.

-20 Smith K, Semple D, Bhandari S, Seymour AM: Cellular basis of uraemic cardiomyopathy: a role for erythropoietin? Eur J Heart Fail 2009;11:732-738.
1 van der Zee S, Baber U, Elmariah S, Winston J, Fuster V: Cardiovascular risk factors in patients with chronic kidney disease. Nat Rev Cardiol 2009;6:580-589.

22 Kovesdy CP, Kalantar-Zadeh K: Review article: biomarkers of clinical outcomes in advanced chronic kidney disease. Nephrology (Carlton) 2009; 14:408-415.

23 Wali RK, Wang GS, Gottlieb SS, Bellumkonda L, Hansalia R, Ramos E, Drachenberg C, Papadimitriou J, Brisco MA, Blahut S, Fink JC, Fisher ML, Bartlett ST, Weir MR: Effect of kidney transplantation on left ventricular systolic dysfunction and congestive heart failure in patients with end-stage renal disease. J Am Coll Cardiol 2005;45:1051-1060.

24 Hawkins S, Wiswell R: Rate and mechanism of maximal oxygen consumption decline with aging: implications for exercise training. Sports Med 2003;33:877-888.

$>25$ Anderson S, Halter JB, Hazzard WR, Himmelfarb J, Horne FM, Kaysen GA, Kusek JW, Nayfield SG, Schmader K, Tian Y, Ashworth JR, Clayton CP, Parker RP, Tarver ED, Woolard NF, High KP, workshop participants: Prediction, progression, and outcomes of chronic kidney disease in older adults. J Am Soc Nephrol 2009;20:11991209.
26 Shlipak MG, Katz R, Kestenbaum B, Fried LF, Siscovick D, Sarnak MJ: Clinical and subclinical cardiovascular disease and kidney function decline in the elderly. Atherosclerosis 2009;204:298-303.

27 Franklin BA: Survival of the fittest: evidence for high-risk and cardioprotective fitness levels. Curr Sports Med Rep 2002;1:257-259.

28 McCullough PA: Why is chronic kidney disease the 'spoiler' for cardiovascular outcomes? J Am Coll Cardiol 2003;41:725-728.

2929 Akhter MW, Aronson D, Bitar F, Khan S, Singh H, Singh RP, Burger AJ, Elkayam U: Effect of elevated admission serum creatinine and its worsening on outcome in hospitalized patients with decompensated heart failure. Am J Cardiol 2004;94:957-960.

30 Stenvinkel P, Carrero JJ, Axelsson J, Lindholm B, Heimbürger O, Massy Z: Emerging biomarkers for evaluating cardiovascular risk in the chronic kidney disease patient: how do new pieces fit into the uremic puzzle? Clin J Am Soc Nephrol 2008;3:505-521. 